Annals of International Medical and Dental Research

E-ISSN: 2395-2822 | P-ISSN: 2395-2814

Vol-8, Issue-1 | January-February 2022

DOI: 10.53339/aimdr.2022.8.1.21

Page no- 159-167 | Section- Research Article (Physiology)

\title{
Predominancy of Coping Styles in Patients with Type II Diabetes in Low Socio Economic Status Groups
}

\author{
Selvakumar Jagannathan ${ }^{1 *}$, Kannan Ramiah $^{2}$, R. Valarmathy Selvakumar ${ }^{3}$
}

\begin{abstract}
${ }^{1}$ Associate Professor, Department of Physiology, Sri Muthukumaran Medical College Hospital \& Research Institute, Chennai, Tamil Nadu, India.

Email id: drjskmddm@yahoo.co.in

Orcid ID: 0000-0002-5664-4783

2Associate Professor, Institute of Physiology \& Experimental Medicine, Madras Medical College, Chennai, Tamil Nadu, India.

Email: drrrkannan1992@yahoo.co.in

Orcid ID: 0000-0001-5940-7401

${ }^{3}$ Consultant Psychologist, Sivam 3rd Mind Counselling \& Psychotherapy Center for Rehabilitation, Chennai, Tamil Nadu, India. Email: valarmathyselvakumar@yahoo.com

Orcid ID: 0000-0003-4722-8881

${ }^{*}$ Corresponding author
\end{abstract}

Received: 09 October 2021

Revised: 28 November 2021

Accepted: 06 December 2021

Published: 22 December 2021

\begin{abstract}
Background: Coping style is a person's characteristic strategies used in response to life problems or traumas. Coping serves a protective function. This study aims to examine the impact of coping styles predominance in the training programme given to patients with type II diabetes of low socioeconomic status group.30 patients with type II diabetes of low socioeconomic status group were selected using purposive sampling from the diabetic clinic for the assessment of coping style. Coping style was assessed using "Coping styles of adults with Type 1 and Type 2 diabetes" by Karlsen and Bru (1998). Paired t-test was used to assess the effectiveness of coping styles enhancement training programme for patients with type II diabetes. The study revealed that there is significant increase in the level of coping styles of patients with type II diabetes due to coping styles enhancement training programme. Methods: ?. Results: ?. Conclusion:?.
\end{abstract}

Keywords:- Type II diabetes and coping styles.

\section{INTRODUCTION}

Coping serves a protective function that can be exercised in three ways: 1) by eliminating or modifying stressful conditions; 2) by perceptually controlling the meaning of the stressor; or 3) by keeping emotional consequences in bounds. $[1,2]$ Coping style is a person's characteristic strategies used in response to life problems or traumas. These can include thoughts, emotions or behaviors. Nancy schimelpfening, 2011 Pearlin and Schooler, who define coping as behavior that protects people from being psychologically harmed by problematic social experiences. $[3,4]$

In other words, coping allows people to use various skills to manage the difficulties they face in life.[5] Lazarus and Folkman believe that each individual represents a unique combination of individual and environmental factors and that stressors result from personenvironment interactions, which cause the person to appraise the situation, appraise the coping resources that are available to him or her, and employ a repertoire of coping behaviors. $[6,7]$ The other commonly used 
Annals of International Medical and Dental Research

E-ISSN: 2395-2822 | P-ISSN: 2395-2814

Vol-8, Issue-1 | January-February 2022

DOI: 10.53339/aimdr.2022.8.1.21

Page no- 159-167 | Section- Research Article (Physiology)

definition and who define it as "constantly changing cognitive and behavioral efforts to manage specific external and/or internal demands that are appraised as taxing or exceeding the resources of the person. [8] Shortterm effects of the response to the stressor include psychological and physiological changes. Long-term effects include psychosocial well-being, social functioning, and somatic health. The overall effectiveness of the stress-coping process places the individual in a position of being relatively resistant or vulnerable to further stress. Yi-Frazier JP et al, Investigated the resilience resources and coping profiles of diabetes patients.[9] Their study demonstrated a link between maladaptive coping and low resilience, suggesting that resilience impacts one's ability to manage the difficult treatment and lifestyle requirements of diabetes. Zhang et al, identified and compared different coping styles of adults with Type 1 and Type 2 diabetes.10] The results indicated that there was ample potential for improving active task orientation of adults with diabetes. It should, however, be of some concern that improving active coping may be associated with an increase in selfblaming. Newbury-Birch et al, examined the degree to which clinical indicators, coping styles and perceived support from healthcare professionals and family are related to diabetes-related distress. [11,12] Results from the regression analyses showed a greater variance in emotional distress accounted for by coping styles (21.3\%) and perceived support $(19 \cdot 7 \%)$ than by clinical indicators $(5.8 \%)$. 13$]$ They found that healthcare providers should pay more attention to non-clinical factors such as coping styles and social support, when addressing diabetes-related distress. They should also be aware that interventions based on psychosocial approaches may primarily influence distress, and not necessarily metabolic control. Huang et al, aimed to evaluate the relationship between depression, coping strategies, glycemic control and patient compliance in type 2 diabetic patients. ${ }^{[14]}$ It was concluded that Likelihood of depression was frequent, consistent with literature and was associated with gender, educational status, coping strategies, duration of diabetes and patient compliance with treatment in our study. Screening for depression and patient education may improve the quality of life in diabetic patients. Stanisławski $K$ et al, examined the contribution of health behaviors (self-management and coping), quality of care, and individual characteristics (depressive symptoms, self-efficacy and illness representations)as mediators in the relationship between socioeconomic status (SES) and glycemic control.[15] To improve glycemic control of patients with low SES, professionals should regularly screen for depression, offering treatment when needed, and pay attention to patients' illness representations and coping strategies for handling stress related to their chronic disease. They should also support patients in improving their self-management skills for a healthy diet. $[16]$

\section{MATERIAL AND METHODS}

\section{Objective}

The present study aims to assess the effectiveness of coping styles enhancement training programme for patients with type II diabetes of low socioeconomic status group. The objective of the present study is to increase 
Annals of International Medical and Dental Research

E-ISSN: 2395-2822 | P-ISSN: 2395-2814

Vol-8, Issue-1 | January-February 2022

DOI: 10.53339/aimdr.2022.8.1.21

Page no- 159-167 | Section- Research Article (Physiology)

the level of coping styles of people with type II diabetes through coping styles enhancement training programme.

\section{Hypothesis}

There will be no significant increase in the level of coping styles of people with type II diabetes after coping styles enhancement training programme.

\section{Research Design}

\section{Ethical clearance}

Proper ethical clearance was obtained from the institution of ethics committee

R.NO:46/ IES-SMMCHRI/ approval projects / p.no.2/8 /IES/dated 06.06.201906.06.2019

Purposive sampling technique and Pre and post test experimental design without control group was used in the present study.

\section{Sample}

The sample of 30 patients with type II diabetes of low socioeconomic status group was selected from diabetic clinic from Muthukumaran medical college \& RI ,Chennai for the assessment of effectiveness of coping style enhancement training programme. The information of the people with type II diabetes with regard to demographic variables such as age, gender, education, employment, marital status and socio economic status are as follows: out of 30 people with type II diabetes, 12 people with type II diabetes belonged to the age group of 30-45 and 18 people with type II diabetes belonged to the age group of $46-60 ; 20$ people with type II diabetes were men and 10 people with type II diabetes were women;12 people with type II diabetes were non graduated and 18 people with type II diabetes were graduated;13 people with type II diabetes were unemployed and 17 people with type II diabetes were employed; 1 person with type II diabetes were unmarried and 29 people with type II diabetes were married ; 18 people with type II diabetes belonged to middle income group and 12 people with type II diabetes belonged to high income group.

\section{Tool}

Coping style was assessed using "Coping styles of adults with Type 1 and Type 2 diabetes" Description of tool Coping style was assessed using "Coping styles of adults with Type 1 and Type 2 diabetes" by Stanisławski et al.[15] Cronbach's alpha vary between 0.70 and 0.85 and it has proved validity. The sub-scale mean scores were categorized into four groups: (1) 'Very seldom use of coping style'; scores within the low quarter of the scoring range indicate typical use of response alternatives 'don't do this at all' through 'do this a little bit'; (2) 'Seldom use of coping style'; scores within the low middle quarter of the scoring range indicate typical use of response alternatives 'do this a little bit'; (3) 'Occasional use of coping style'; scores within the high middle quarter of the scoring range indicate typical use of response alternatives 'do this a medium amount'; and (4) 'Frequent use of coping style; scores within the high quarter of the scoring range indicate typical use of response alternatives 'do this a medium amount' through 'do this a lot'. Prior to the categorization, the scores for the diabetes coping measure were adjusted by multiplying each score by $4 / 5$ to have the same scoring interval as the other sub-scales ranging from 1- 
Annals of International Medical and Dental Research

E-ISSN: 2395-2822 | P-ISSN: 2395-2814

Vol-8, Issue-1 | January-February 2022

DOI: 10.53339/aimdr.2022.8.1.21

Page no- 159-167 | Section- Research Article (Physiology)

4.Diabetes type was determined by self-report, asking whether the respondents had Type 1 or Type 2 diabetes.

\section{Procedure}

Phase I: Pre test was conducted using "Coping styles of adults with Type 1 and Type 2 diabetes" by Huang et al to assess the level of coping style. People with type II diabetes who had low level of coping styles were selected for coping style enhancement training programme.

Phase II: Intervention - coping styles enhancement training programme was conducted to people with type II diabetes. It includes a practical method of coping skills training for people with diabetes: Coping strategies are an important, yet neglected, aspect of diabetes care, especially in the elderly. Diabetes is a chronic disorder, the diagnosis of which is accompanied by considerable physical and mental stress. Coping mechanisms can also be classified as unconscious cognitive processes, e.g., projection, denial, and conscious cognitive processes, e.g., self blame, other blame, rumination and catastrophizing. The conscious coping strategies are self regulating methods of emotion regulation and stress management. Coping can be classified as problem - focused or emotion -focused. The problem -focused coping strategies comprise all coping mechanisms which directly address the stressor, while emotion -focused coping strategies regulate the emotions associated with the stressor. Problem -focused strategies are thought to be more functional, but this classification is not adequate. Problem oriented coping can further be classified as cognitive (thought patterns related to coping) and behavioral (action related to coping). Cognitive coping skills are usually stable for any individual, as she or he tends to behave in a similar manner when faced with various stresses. However, they can be changed, learned, unlearned and influenced by oneself, or through influence of others. Clinical psychological literature mentions various cognitive coping strategies. These include negative mechanisms such as self blame, i.e., blaming oneself for what one has experienced; catastrophizing, i.e., emphasizing the terror of the experience; and other -blame, i.e., blaming others for one's own experiences and rumination, i.e., thinking all the time about the negative event. Positive mechanisms of coping include acceptance, i.e., resigning oneself to what has happened; positive refocusing, i.e., thinking of other, pleasant matters instead of the negative event; refocus on planning, i.e., planning steps to deal with the event; positive reappraisal, i.e., attaching a positive meaning to the negative event; and putting into perspective, i.e., playindown the seriousness of a stressor event. Functional or positive coping mechanisms are essential to ensure health of any individual, but are even more important for those with a chronic disease such as diabetes mellitus.

\section{Delearning Negative Skills}

Once an inventory of coping skills is made, the next step is to relearn negative or dysfunctional kills. Rumination, catastrophizing and selfblame are strategies which are counterproductive, and are related to psychopathology, as well as poor quality of life and clinical outcomes. The patient should be encouraged to identify negative cognitions and 
Annals of International Medical and Dental Research

E-ISSN: 2395-2822 | P-ISSN: 2395-2814

Vol-8, Issue-1 | January-February 2022

DOI: 10.53339/aimdr.2022.8.1.21

Page no- 159-167 | Section- Research Article (Physiology)

exercise self- will to stop them. Examples of rumination will include thinking about diabetes the whole day, worrying about an insulin injection four hours before it is due, and having day dream about an insulin injection four hours before it is due, and having day dream about developing kidney failure "because I saw it on T.V". Catastrophizing manifests as 'I am going to die today because of diabetes'. 'The world will come to an end because of diabetes' or 'No one will ever love because I have an incurable disease'. Self -blame is a common selfdefeating coping mechanisms, in which the patient feels 'I ate too many chocolates -it's my fault I got diabetes' or I must have committed sins in my previous life - now I must suffer from diabetes in this life.

\section{Learning Positive Skills}

Once, the patient has learnt how to identify negative coping skills, or he can be trained to use positive skills. The easiest protective coping strategies to learn are positive refocusing and positive reappraisal, and are good starting points for people with diabetes. Positive refocusing means changing thought patterns and focusing on pleasant, happy and unrelated matters, instead of original stressor, such as diabetes. The patient can learn how to replace negative diabetes -related cognition with thoughts about things such as picnics, vacations, family or friends. An example of positive refocusing would be thinking about an upcoming marriage or social function or day dreaming about a close friend or spouse. This is a method of overcoming rumination. Positive reappraisal is the opposite of catastrophizing and involves a reassessment of one's condition, with focus on its positive aspects. 'Diabetes has helped me improve my self - confidence', 'Diabetes management has made me more balanced', or 'Diabetes teaches us self - control' are ways of finding a positive aspect of the disease. 'Having diabetes gives me the motivation to work harder and be successful' is another example of positive reappraisal, which should be encouraged. This overlaps with 'focus on planning' which means thinking about future activities and action, e.g., 'I will go for a diabetes camp this weekend', or 'I will join healthy cooking classes'. Other blame is a coping mechanism which is used by some to explain diabetes. Witchcraft, voodoo, tantricism and envious relatives or spouses are blamed for diabetes, and become a target for hatred and dislike. Putting into perspective is a positive or protective mechanism whereby one analyzes her or his life, and realizes that diabetes and other illness are just one aspect of existence. 'Diabetes will not prevent me from living life' is a way of putting the disease into perspective, as is 'I can continue to play cricket, watch movies and attend dance classes, so why bother about diabetes? 'Reinforcement Once negative mechanisms have been controlled, and positive or protective mechanisms learnt, it is a matter of practice. Support from friends, family and the diabetes care team help the patient strengthen her or his positive mechanisms, until they become not only a part of coping with diabetes, but with life in general. Sessions with the clinical psychologist at regular ( 3 to 6 monthly) intervals should be arranged to ensure continued motivation, and to sort out any problems that he individual patient might face. Group Therapy /Peer Counseling Coping skills can also be taught in groups,and by peers. These approaches are cost- and time efficient, and may be more 
Annals of International Medical and Dental Research

E-ISSN: 2395-2822 | P-ISSN: 2395-2814

Vol-8, Issue-1 | January-February 2022

DOI: 10.53339/aimdr.2022.8.1.21

Page no- 159-167 | Section- Research Article (Physiology)

effective in improving patient motivation as well. Key skills for healthy coping are problem solving and goal setting appraising problems and challenges, generating alternatives for dealing with them, testing those alternatives, and assessing results; Social skills, including how to express one's feelings and choices effectively ; Cognitive skills for avoiding "making mountains out of molehills" ; Stress management skills like relaxation and meditation .In summary, diabetes is a longterm stressor that has the potential for patients to have difficulty in coping with the day-today management of diabetes. Clinicians can evaluate their clients' coping abilities in both formal and informal ways, and this information can be used to assist the patients in developing better coping skills. Such improved coping skills may assist clients in achieving better metabolic control and quality of life. Phase III: After a gap of one month, post test was conducted using "Coping styles of adults with Type 1 and Type 2 diabetes" to find out whether there will be significant increase in coping styles of people with type II diabetes after coping styles enhancement training programme.

Statistical analysis Paired t- test was used to assess the effectiveness of coping styles enhancement training programme.

Table 1: showing the level of significance of coping styles and its dimensions of people with type II diabetes.

\begin{tabular}{|c|c|c|c|c|c|c|}
\hline Sl. No & Dimensions of coping style & \multicolumn{2}{|c|}{ Pre test $(n=30)$} & \multicolumn{2}{|c|}{ Post test $(n=30)$} & t-value \\
\hline & & Mean & SD & Mean & SD & \\
\hline 1 & Integration & 15.5 & 4.5 & 12.21 & 4.42 & $2.8^{* *}$ \\
\hline 2 & Resignation & 8.0 & 3.8 & 5.31 & 2.42 & $3.27^{* *}$ \\
\hline 3 & Seeking social support & 15.5 & 5.12 & 29.80 & 1.60 & $14.58^{* *}$ \\
\hline 4 & Denial & 13.37 & 4.40 & 10.13 & 3.46 & $3.17^{* *}$ \\
\hline 5 & Seeking knowledge & 8.03 & 3.16 & 15.37 & 0.74 & $12.22^{* *}$ \\
\hline 6 & Planning & 7.4 & 3.04 & 13.88 & 1.28 & $10.76^{* *}$ \\
\hline 7 & Self blame & 10.11 & 1.58 & 5.45 & 2.06 & $9.54^{* *}$ \\
\hline 8 & Total & 77.78 & 16.3 & 92.06 & 8.83 & $4.23^{* *}$ \\
\hline
\end{tabular}

** Significan $t$ at 0.01 level

\section{RESULTS \& DISCUSSION}

Results showed that there is a significant increase in the level of coping styles of people with type II diabetes after coping styles enhancement training programme. [Table 1] shows the level of significance of coping styles of people with type II diabetes. Pre and post test mean value of coping style is 77.79 and
92.06 respectively; pre and post test standard deviation of coping style is 16.34 and 8.84 respectively which shows significant increase in the level of coping styles of people with type II diabetes after coping styles enhancement training programme. The sub scales such as integration, resignation, denial and self blame shows significant decrease in the mean and 
Annals of International Medical and Dental Research

E-ISSN: 2395-2822 | P-ISSN: 2395-2814

Vol-8, Issue-1 | January-February 2022

DOI: 10.53339/aimdr.2022.8.1.21

Page no- 159-167 | Section- Research Article (Physiology)

standard deviation which implies that the coping styles training programme is effective enough to decrease the negative sub scales. Similiarly, the subscales such as seeking social support, seeking knowledge and planning shows significant increase in the level of mean and standard deviation which implies that the coping style training programme is effective in increase the positive sub scales. The $t$-value of coping style 4.21 implies statistically significant. Jaser et al, (2009) suggested that certain coping styles might moderate the association of psychological stress with anxiety and depressive symptoms in Chinese patients with Type 2 diabetes.[17] Trikkalinou et al, summarized recent literature on approaches to supporting healthy coping in diabetes in 2 specific areas: (1) the impact of different approaches to diabetes treatment on healthy coping and (2) the effectiveness of interventions specifically designed to support healthy coping. [18] Evidence suggests that treatment choice may significantly influence quality of life, with treatment intensification in response to poor metabolic control often improving quality of life. The recent literature provides support for a variety of healthy coping interventions in diverse populations, including diabetes self-management education, support groups, problem-solving approaches, and coping skills interventions for improving a range of outcomes; cognitive behavior therapy and collaborative care for treating depression; and family therapy for improving coping in youths. ${ }^{19]}$ Healthy coping in diabetes has received substantial attention in the past 5 years. A variety of approaches show positive results. Research is needed to compare the effectiveness of different approaches in different populations and determine how to overcome barriers to intervention dissemination and implementation. Zhang et al, concluded that hardiness and coping strategies affect occupational life quality for both people suffering from Type II diabetes and healthy people.[20] Therefore, it was proposed that people strengthen their hardiness and coping strategies, in order to improve their occupational life quality. Low coping skills may cause a person problem in relationships and work. A lack of coping skills may occur during childhood and play out through adulthood or may be a result of a traumatic experience that occurred in the person's past. Depression may take over a person's life, making it hard to cope with anything. Writing down feelings associated with depression can help in developing coping skills.[21] In most instances of depression, therapy may provide a helpful outlet to start working on coping with problems. Children growing up without a positive support system may never have learned proper coping skills, according to Psychology Today. Establishing a support system through friendships, therapy or a support group may help a person begin to develop necessary coping skills for everyday life. The people in the support system should understand low coping skills and help the person use support when necessary. Many people never develop emotional maturity, according to Mental Help.net. This may cause problems with practicing appropriate coping skills. If a traumatic experience happened during childhood or young adulthood, this may have halted the ability to become emotionally mature Only by dealing with the traumatic experience can a person begin to learn appropriate coping skills to aid in his emotional maturity. If a person spends the 
Annals of International Medical and Dental Research

E-ISSN: 2395-2822 | P-ISSN: 2395-2814

Vol-8, Issue-1 | January-February 2022

DOI: 10.53339/aimdr.2022.8.1.21

Page no- 159-167 | Section- Research Article (Physiology)

majority of time alone, they may not learn positive coping skills. Isolation can lead to bigger problems, such as depression, suicidal thought patterns and lack of relationships.[22] Social activities will help in dealing with problems within the culture and allow the person to consistently associate with other people. Due to problems in childhood, many people develop defense mechanisms that hinder coping skills, according to Psychology Today. Defense mechanisms can cause problems because a denial of reality occurs when defense mechanisms come into play. Since defense mechanisms form an escape from reality, encouraging someone to face reality will allow them to develop appropriate

\section{REFERENCES}

1. Jali MV, Kambar S, Jali SM, Gowda S. Familial early onset of type-2 diabetes mellitus and its complications. N Am J Med Sci. 2009;1(7):377-80. doi: 10.4297/najms.2009.7377.

2. King H, Aubert RE, Herman WH. Global burden of diabetes, 1995-2025: prevalence, numerical estimates, and projections. Diabetes Care. 1998;21(9):1414-31. doi: 10.2337/diacare.21.9.1414.

3. Mensing C, Boucher J, Cypress M, Weinger $\mathrm{K}$, Mulcahy K, Barta P, et al. National standards for diabetes self-management education. Task Force to Review and Revise the National Standards for Diabetes Self-Management Education Programs. Diabetes Care. 2000;23(5):682-9. doi: 10.2337/diacare.23.5.682.

4. Nicolucci A, Kovacs Burns K, Holt RI, Comaschi M, Hermanns N, Ishii H, et al; DAWN2 Study Group. Diabetes Attitudes, Wishes and Needs second study (DAWN2 ${ }^{\mathrm{TM}}$ ): cross-national benchmarking of diabetes-related psychosocial outcomes for people with diabetes. Diabet Med. 2013;30(7):767-77. doi: 10.1111/dme.12245.

5. Revicki DA, Osoba D, Fairclough D, Barofsky I, Berzon R, Leidy NK, Rothman M. Recommendations on health-related quality of life coping skills. When the stressor is diabetes, people with diabetes are not able to eliminate the condition, so they need to find ways to make the condition manageable. Further, diabetes management is a full-time job; thus, coping with diabetes is also a full-time job. From the findings, it can be stated that the coping styles enhancement training programme given to the people with type II diabetes is effective.

\section{CONCLUSIONS}

People with type II diabetes showed a significant increase in their level of coping styles after coping styles enhancement training programme.

research to support labeling and promotional claims in the United States. Qual Life Res. 2000;9(8):887-900. doi: 10.1023/a:1008996223999.

6. Venkataraman K, Kannan AT, Mohan V. Challenges in diabetes management with particular reference to India. Int J Diabetes Dev Ctries. 2009;29(3):103-9. doi: 10.4103/0973-3930.54286.

7. Freire C, Ferradás MDM, Regueiro B, Rodríguez S, Valle A, Núñez JC. Coping Strategies and SelfEfficacy in University Students: A Person-Centered Approach. Front Psychol. 2020;11:841. doi:10.3389/fpsyg.2020.00841

8. Parildar H, Cigerli O, Demirag NG. Depression, Coping Strategies, Glycemic Control and Patient Compliance in Type 2 Diabetic Patients in an endocrine Outpatient Clinic. Pak J Med Sci. 2015;31(1):19-24. doi: 10.12669/pjms.311.6011.

9. Yi-Frazier JP, Smith RE, Vitaliano PP, Yi JC, Mai S, Hillman M, Weinger K. A Person-Focused Analysis of Resilience Resources and Coping in Diabetes Patients. Stress Health. 2010;26(1):51-60. doi: 10.1002/smi.1258.

10. Zhang CX, Chen YM, Chen WQ. Association of psychosocial factors with anxiety and depressive symptoms in Chinese patients with type 2 diabetes. Diabetes Res Clin Pract. 2008;79(3):523-30. doi: 10.1016/j.diabres.2007.10.014. 
Annals of International Medical and Dental Research

E-ISSN: 2395-2822 | P-ISSN: 2395-2814

Vol-8, Issue-1 | January-February 2022

DOI: 10.53339/aimdr.2022.8.1.21

Page no- 159-167 | Section- Research Article (Physiology)

11. Newbury-Birch D, Kamali F. Psychological stress, anxiety, depression, job satisfaction, and personality characteristics in preregistration house officers. Postgrad Med J. 2001;77(904):109-11. doi: 10.1136/pmj.77.904.109.

12. Karimi S, Jaafari A, Ghamari M, et al. A Comparison of Type II Diabetic Patients With Healthy People: Coping Strategies, Hardiness, and Occupational Life Quality. Int J High Risk Behav Addict. 2016;5(1):e24169.

13. Karlsen B, Oftedal B, Bru E. The relationship between clinical indicators, coping styles, perceived support and diabetes-related distress among adults with type 2 diabetes. J Adv Nurs. 2012;68(2):391-401. doi: 10.1111/j.1365-2648.2011.05751.x.

14. Huang CY, Lai HL, Lu YC, Chen WK, Chi SC, Lu CY, Chen CI. Risk Factors and Coping Style Affect Health Outcomes in Adults With Type 2 Diabetes. Biol Res Nurs. 2016;18(1):82-9. doi: $10.1177 / 1099800415569845$.

15. Stanisławski K. The Coping Circumplex Model: An Integrative Model of the Structure of Coping With Stress. Front Psychol. 2019;10:694. doi:10.3389/fpsyg.2019.00694

16. Schneiderman N, Ironson G, Siegel SD. Stress and health: psychological, behavioral, and biological determinants. Annu Rev Clin Psychol. 2005;1:607628. doi:10.1146/annurev.clinpsy.1.102803.144141

17. Jaser SS, Patel N, Xu M, Tamborlane WV, Grey M. Stress and Coping Predicts Adjustment and
Glycemic Control in Adolescents with Type 1 Diabetes. Ann Behav Med. 2017;51(1):30-38. doi:10.1007/s12160-016-9825-5

18. Trikkalinou A, Papazafiropoulou AK, Melidonis A. Type 2 diabetes and quality of life. World J Diabetes. 2017;8(4):120-129. doi:10.4239/wjd.v8.i4.120

19. Anjana RM, Ali MK, Pradeepa R, Deepa M, Datta M, Unnikrishnan $R$, et al. The need for obtaining accurate nationwide estimates of diabetes prevalence in India - rationale for a national study on diabetes. Indian J Med Res. 2011;133(4):369-80.

20. Zhang B, Nilsson ME, Prigerson HG. Factors important to patients' quality of life at the end of life. Arch Intern Med. 2012;172(15):1133-1142. doi:10.1001/archinternmed.2012.2364

21. Burckhardt CS, Archenholtz B, Bjelle A. Measuring the quality of life of women with rheumatoid arthritis or systemic lupus erythematosus: a Swedish version of the Quality of Life Scale (QOLS). Scand J Rheumatol. 1992;21(4):190-5. doi: $10.3109 / 03009749209099220$.

22. de Ornelas Maia AC, Braga Ade A, Paes F, et al. Comorbidity of depression and anxiety: association with poor quality of life in type 1 and 2 diabetic patients. Clin Pract Epidemiol Ment Health. 2013;9:136-141. doi:10.2174/1745017901309010136

Source of Support: Nil, Conflict of Interest: None declared 